\title{
5. Ancient and modern footprints: music and the mysteries of Lake Mungo
}

\author{
Adam Shoemaker
}

A moment. September 2005. As a group of us walked through a meandering sand path in outback Australia, bordered with saltbush, we crested a rise. Below was an unremarkable basin: greyish brown, sparse and treeless. The colour of the cloudy sky mirrored the hue of what lay beneath our feet. Around us were the enveloping murmur of wind and the crunch of boots on sand. There was nothing to suggest that it was in any way special; it could just as easily have been any one of the hundreds of such vistas in the Willandra Lakes area, located in the far south-western corner of the state of New South Wales about 120 kilometres north-east of the Victorian town of Mildura.

What lay in front of us, however, was exceedingly special. It was a record of human habitation more than 20000 years old-an evocation of lived heritage, which, in its depth and breadth, was unlike any other on the face of the Earth. It was a footprint site, one that suggested the activities, the stories and the sounds of Indigenous Australia over millennia. It was also a unique place in which echoes of the past - visual and aural-were unified. Ironically, we were all silenced - almost struck dumb - by the impressiveness of a place that was itself so full of centuries of sound.

Of course, the entire Willandra Lakes World Heritage Area is unique. Together with the Great Barrier Reef and Kakadu National Park, it is one of Australia's three most significant sites of global patrimony. In 1968, the oldest Indigenous Australian skeletal remains to be discovered in mainland Australia were uncovered on the shores of Lake Mungo, in the heart of the Willandra. That female skeleton was eventually dated to an age of more than 40000 years: 'the oldest demonstrated ritual cremation anywhere in the world' (Lawrence 2006:17).

This discovery, which colloquially became known as 'Mungo Lady', revolutionised global perceptions of the nature and longevity of Aboriginal and Torres Strait Islander life in Australia. It gave rise to various new theories of human occupation of the island continent, to the interrelationship between inland waterways and nomadic peoples and it opened up scholarly interpretations of what is now called 'palaeobiology' and 'palaeopathology'. These became sites of enormous pride for the Indigenous elders of the three tribes in the area: the Paakantyi, the Mutthi Mutthi and the Ngiyampaa. The continuing, central role 
of those traditional owners is one of the key elements of the entire Willandra area.

In 1981, the area was officially designated a World Heritage Area by UNESCO. The proclamation of that status was recognised in September 2006 by a commemorative festival, which featured storytelling, re-enactment and, significantly, musical performance. Despite its scientific and Indigenous significance, however, the area popularly known as Lake Mungo or just Mungo is the least known (and least visited) of the Australian World Heritage zones. More than half a million tourists travel to the Great Barrier Reef and to Kakadu National Park annually; the figure for the Willandra is approximately 10 per cent of that number, or just less than 50000 per annum. As I will argue, however, the scientific, historical, cultural, performative and archaeological importance of the Willandra is - at this very moment - more significant than it has ever been.

For this is a truly interdisciplinary story, one that surprises, confounds expectations and that has the potential to-yet again-revolutionise our understanding of ancient history and of original sound-scapes. It is one that brings the humanities, the creative arts and the sciences together in an intellectual coalition of great strength. It is one in which both senses of the term 'fieldwork' are comprehensively explored: where experiential education and (literally) groundbreaking archaeological research are aligned in a unique way. It is a project in which the contribution to Indigenous history by Aboriginal and Torres Strait Islander people themselves is an irrepressible force. It is one of the clearest examples of the intersection between globalisation and Indigenous culture - a juncture that holds both risks and the potential for social justice as well as recognition.

Nearly four years ago, Mary Pappin, Jr- one of three Indigenous trainee rangers in the Willandra - walked over the rise that I mentioned at the outset, entered into a large pond-like depression and noticed a single, remarkable echo of the past etched into the ground: an unmistakably human footprint. That careful observation by Pappin has changed, yet again, the perspective of the Lake Mungo National Park (whose famous human skeletal remains were discovered some kilometres away). Working with the respected archaeologist Professor Stephen Webb, the Three Traditional Tribal Groups Elders Council authorised the painstaking excavation of the area. No-one could have predicted the extent, the import or the vividness of that discovery.

From one partially obscured impression, the team of Indigenous and non-Indigenous researchers uncovered, by September 2005, more than 250 footprints. By December of that year, the number had risen to 450 and, according to Webb, there are likely 600-700 prints in total in just that one area; it is, quite simply, the most significant footprint site on the planet. Expressing this another 
way, there are more extant footprints in the Willandra than in all known sites in the rest of the world combined (Catalyst, ABC Television, 31 August 2006). What is particularly remarkable is the incredible clarity of the record. Bioluminescence, or optically stimulated luminescence (OSL), testing has established that the tracks are truly ancient. They were formed approximately 20000 years ago but they are so detailed and evocative that it seems one is following the walkers just minutes after they were present. One sees the unmistakable signs of mud between the toes, of children who have leapt and gambolled and changed directions suddenly to follow their mothers, of five men who were all running very quickly in the same direction.

I argue that the site is also one that is imbued and 'inspirited' with sounds - of the era 20 centuries ago and the present day. And, on the day I was introduced to it with students from our university, we examined one of the most baffling footprints I have ever viewed. There were at least 14 impressions of what everyone termed the 'one-legged man': these were right footprints only, each separated by more than one metre, with no signs of hopping or vaulting. The size of the foot was very large - size 11 or 12 in North American parlance - which scientists tell us equates to a height of at least 194 centimetres (Webb et al. 2006). There were audible gasps among the entire group when faced with this seeming mystery.

The overarching emotions shared by everyone were reverence and awe. A footprint - the most simple of human records, and one that is so evanescent it is normally washed away on the beach by the incoming tide - was here, frozen in time in a way that was incredible. It is, therefore, a human site, one that provides a glimpse of ancient history as a simulacrum. It is an Indigenous Australian site that has great spiritual significance as an echo of specifically Aboriginal ancestry. It is explicitly an artistic site in which the human design of footprints forms an unmistakeable canvas - a pattern that is as entrancing as it is creative. It is an irrepressibly musical venue, in which the acoustic environment comes to the fore in a myriad ways. Thus, faced with its spectacle, all viewers become intensely focused listeners as well. All present are transformed to become members of an audience that apprehends real and imagined sounds, past and present alike: those outside the frame of the site itself (such as the echoes of far-off thunder) and the literal echoes of the past suggested by the tracks themselves.

Finally, this is a scientific site, where the latest technique of, for example, ground-penetrating radar shows that there are 22 separate tracks and, astonishingly, that what is visible is about only 10 per cent of what could potentially be revealed. As Professor Steve Webb has stated, 'There could be seven or eight layers of footprints there laying [sic] on top of each other; eight 
phases of these people hunting and gathering' in a form of three-dimensional revelation (Personal communication, 4 August 2006).

All of these dimensions of the site are intertwined in a unique partnership: non-Aboriginal students of archaeology are able to visit the area only when given the permission and careful directions of Indigenous elders, while non-Indigenous pastoralists and scientists pool their knowledge, as well as their trust, in so doing. The overarching sense of being there is, however, one of respectful mystery - of sound, even within the silence. And of storytelling.

For the site is imbued with an inescapable sense of artistic narrative. The immediacy and familiarity of the record immediately lead to hypotheses, not only about the age of the area but about the type of soil — which is magnacite, a rare amalgam of magnesium and carbonate - which enabled the mud prints to be 'frozen' in time for 20 millennia. All the theories concerned imagined behaviour and the recording of a very personal sense of history. How could it be that a one-legged man could have survived 20000 years ago? How did he lose his leg - was it burned in a fire? Was one leg bound against his body? Did he carry a walking stick for support (and why were there no indications of depressions from it in the mud)? And how could he possibly have hopped so far when no human beings alive today could have done so? Could he have been kneeling on a canoe with his left leg while propelling the watercraft with his right? How could these mysteries be solved?

Perhaps we can say that these mysteries are investigated, if not actually solved, through imagination (this being in a sense the very nature of a hypothesis). As we imagine each possible scenario, each imagined story, sound becomes an even more powerful element. Thus, the 'mind's ear' as well as the 'mind's eye', not to mention the 'mind's action' (the kinetic element), are all brought together on this ancient stage.'

What this indicates is that a particularly powerful sense of performance is present on, and in, the site. This is what is so striking about the Willandra Lakes discovery: that, perhaps, three different types of human experience meet there (in symbolic terms) on the claypan-ancient history, forensic science and the creative, musical arts (there were expressions of dance, of design, of singing, of semiotic marking). There was, in and on the soil, an overriding atmosphere of discovery and-paradoxically - of blindness. For whatever we observed in hypothetical terms, we were all acutely aware of our own limitations, of how we, as latter-day, twenty-first century observers, were probably missing most of the visible signs in front of us.

One of the clearest ways of throwing this paradox into relief is to consider the inspired leadership of the Lake Mungo traditional owners, who decided to invite three Indigenous trackers from Central Australia to visit the footprint site in 2006. The three were traditional Pintupi/Warlpiri people, all of whom had not 
had contact with European Australians until they were in their thirties. According to Professor Webb, who was present at the time, they were completely silent when they first saw the area; then all three began to whisper among one another. The single word they said was 'Djukurrpa', the Pintupi-Luritja term that we in the English-language world have imperfectly translated as 'the Dreaming'. In other words, for the visitors, the footprints were a visible manifestation of continuing religious belief, of the persistence of past sacredness in the present. This was an unsurpassed example of ancient and modern stories coming together in a fascinating moment.

At the same time, the trackers observed an immense amount-far more than anyone else had noticed. They found almost invisible skid-marks, showing where the five running men had thrown spears (unsuccessfully) at their prey-likely a kangaroo. They noted a small physical record where one of the people (perhaps a child) had been doodling in the mud. They were totally unperturbed by the one-legged man and found evidence of small depressions where he had in fact been leaning on a pole while he hopped. They showed where he stopped, where he threw a stick, where he jumped. In the words of Professor Webb, 'these trackers were not at all fazed by the footprints; for them it was simple proof of the fact that if you did not adapt you would die' (Personal communication, 4 August 2006).

Moreover, these insights - the reverential awe of the trackers when first faced with the site, as well as their deep apprehension of its many-layered significance - raise the whole issue of comparative, cross-cultural understanding. Equally, it proves just how indispensable the specialised Indigenous contribution to Australian research can be, not just at Lake Mungo, but wherever human contact has taken place on this continent. At the same time, the depth of the Mungo discovery suggests the profundity of Aboriginal music (and lyrical poetry). Put simply, there is much to sing about at the footprint site.

Consider this from a slightly different perspective: our discovery of a unique landscape such as this one inevitably attunes the senses in a different way. The initial human reaction is one of silence and stillness: the view of the ancient world on display literally takes speech away. A key realisation, however, is that, while speech is silenced, one's hearing is not. Indeed, all the senses are heightened; the visual impressiveness of the array of footsteps makes one look even more closely. One wants to touch the soil, to feel it under bare feet, to try to connect in a kinetic way with the human map of behaviour that has unfolded.

Then, a different form of apprehension takes over. One truly listens in a new way to ambient and imagined sounds: to the wind whistling over the rise; to the echoes of bird calls; to the sounds that our own footprints make on the calciferous surface; even to one's own inspiration (in all senses of that word). 
It is at that precise moment that sounds become translated and transported in striking fashion. And, not surprisingly, this is a moment of blinding inspiration and of revealing insight. What is surprising is that one's individual senses do not suffer as a result of others coming into play: visual and sonic clues act in tandem and are mutually reinforcing.

In this respect, no written essay can do justice to the experience. What a chapter such as this one can do, however, is to signal the fact that the musicological debate about the 'predominance of vision over audition' does not apply in this case. Many theorists have agreed with Murray Schafer, who argued in his landmark 1977 text The Tuning of the World that, '[i]n Western culture truth is not "heard": (as in Jewish religion) but "seen" and that this "contributes to a lack of sonological competence (competence for understanding sound formations) in our culture"' (quoted in Laske 1978:395). In this case, however, where the simple complexity of the Lake Mungo footprint site enriches all of the senses simultaneously, sight and sound do not vie for ascendance. Rather, there is a form of impressive harmony produced by the depth and uniqueness of the human record that surrounds any viewer, any listener, any observer, any hearer of that special environment.

Another way to express this is to say that it is nearly impossible for any human being not to react to the site in this way. It has an inescapable, inbuilt narrative or thrust towards storytelling. It is replete with latent mystery. And, in terms of what has been called 'acoustic ecology' (or the 'study of the effects of the acoustic environment or soundscape on the physical responses or behavioural characteristics of creatures living within it'; Schafer 1977:2), Lake Mungo is like no other Australian landscape. Even more: as small, coloured flags were painstakingly placed next to each footprint by archaeologists and their collaborators to mark the trajectory of each imprint on the soil, the overall visual frame altered again - to produce a different sonic record.

Much as Indigenous sand and bark paintings often portray an inbuilt 'eagle's-eye view' of the landscape, as if the artist were adopting an aerial perspective of special sections of country, the flagged track-ways at Mungo looked, and felt, for all the world like the notations of a musical score. Semiotically, then, the land signifies music and is translated into a musical pattern. Fascinatingly, this applies not just on one plane but on many, so the score is both on the surface and subterranean. This evokes Stephen Muecke's (2004:106-17) powerful observation about the 'subterranean river of blood' in Arrernte culture; proof of the fact that 'the Law' (and evocations of suffering) in Indigenous Australian society are deep matters indeed.

If this is not fascinating enough, there is more-much more. For the location suggests not just current sounds, or the shape and feel of a composition, but ancient sounds of 20000-23000 years ago - and it does all of this at once. Seeing 
the extant prints of a kangaroo that hopped centuries ago immediately conjures up the image of the creature and the sound of its distinctive thumping echo on the ground. Seeing the crisscrossing tracks of children playing brings to life the ambient noise of shrieks of laughter and pleasure. Noting the mark of a spear on magnacite brings to the mind's ear the special sound of skidding wood on sand... and so on.

At every level, therefore, the Lake Mungo site operates like a three-dimensional chess game with an inbuilt sonic register. The site is undoubtedly liberated by science but it is also humanised by musical sounds in translation. It is a performed place in terms of ritual, religion and storytelling, but also via lyricism and music. It is undoubtedly narrational and has intrinsic performativity and it is also - at one and the same time- a natural sound-scape.

In all of these multiple ways, the Lake Mungo discovery proves the appositeness of what Steven Feld (1984) has termed 'qualitative and intensive comparative sociomusicology'. Put another way, particular venues such as Mungo, which are full of sonic and visual meanings, can be thrown into comparative relief to illustrate a whole range of translational conclusions. As Feld (1984:385) continues:

Comparative sociomusicology should take the tough questions and sort them out with the best materials available for detailed comparison: the thorough, long-term historically and ethnographically situated case study. The meaningful comparisons are going to be the ones between the most radically contextualized case examples, and not between decontextualized trait lists.

I agree with him, explicitly and implicitly. I believe that, like a classic Shakespearian play, Lake Mungo provides the stage for imagined and ambient sounds. The surprising aspect is that both can be apprehended simultaneously, and in harmony.

Given all of this significance, it is no wonder that the footprint site - though still relatively unknown - is rapidly changing the face of ancient Australasian history. The discovery featured in the June 2006 issue of National Geographic, a television treatment focusing on the site was aired on the Australian Broadcasting Corporation's science show Catalyst on 31 August 2006, and the Central Australian Aboriginal Media Association (or CAAMA) accompanied the three Central Australian trackers on their journey and was preparing its own documentary treatment of the encounter. One common feature of all of these approaches is that they underline the uniqueness of the Willandra and the incredibly local, specific and grounded nature of the site. It is a visible manifestation of traditional Aboriginal law, in which the real power resides in and beneath the soil in a place of spiritual, scientific, artistic and cultural depth. 
At that very instant, however, in the same few moments that one can read the previous sentence, one realises that the footprint site is also simultaneously a world issue, an artistic challenge and a manifestation of globalisation. This is also, I would argue, a key marker of the contemporary Aboriginal and Torres Strait Islander universe. In this way, the most prominent, the most local and the most grounded signifiers of culture in Australia are simultaneously the most international, the most migratory and the most emblematic of that country's images globally - as relevant in Toronto as they are in Taipei.

Just as the images in the Indigenous Australian section of the recently opened Musée de Quai Branly in Paris conjoin the past and the present in a moment of instantaneous transference, so the footprint site represents a unique coalition between science and the new creative arts. How so? Because every dimension of the external treatment of the footprint site is one of globalism: images of the area are readily downloadable from at least 10 different locations on the Internet (including National Geographic Online) and the importance and putative authenticity of the site were first validated via a major article by Webb and Cupper in the Journal of Human Evolution (accepted and published electronically on 26 October 2005).

Even more: the desires of the Three Traditional Tribal Groups to slowly and steadily control the release of imagery from the footprint site (itself an attempt to assert a measure of Indigenous sovereignty over the discovery) were thwarted because the Journal of Human Evolution posted the relevant article on its web site many weeks before the hardcopy of the journal was released. This led to the inadvertent leaking of the news of the footprint findings more than a month earlier than the elders had planned, forcing them to orchestrate a rapidly organised media release about the track-way just before Christmas 2005.

Therefore, the same communication tools that the elders employed for their media campaign had already robbed them of the means to announce the footprint discovery in a strategic, Aboriginally controlled fashion. It also markedly lessened their ability to exercise the same degree of custodianship over the intellectual property produced by, and inherent in, the site - in particular, the world-wide dissemination of the dramatic colour photographs taken of the footprints. Therefore, all of those factors - unexpected early news of the discovery; the release of (unauthorised) images; the professional trajectory of the international archaeological community-participate in the same three conundrums. These are:

- that indigeneity is often taken as a proxy for timelessness but contemporary time is very much of the essence

- that indigeneity is frequently understood as being incredibly specific to certain landscapes and local cultures, but its validation is always according to putative international standards and categories (whether they be the 
'dating' of deposits, an assessment of the assumed authenticity of records or the dissemination of knowledge)

- that indigeneity is mistakenly thought of as being (like the footprints themselves) solely ancient while its involvement with modern technology is vital, irresistible and subject to continuing change as a condition of existence.

Thus, contemporary science meets the Indigenous arts, aligned in a new moment in which each liberates the other. That said, the Lake Mungo footprint site shows so clearly that while technology cannot be realistically ignored it must be placed in ethical context on each occasion, in each visit, in each article that is written. As ethnomusicologist René Lysloff has written:

Technology privileges researchers, distancing them from the object of research - whether musical or human - and allowing them to control it. Indeed, the sound object becomes a true object: isolated from the noisy chaos of real life in the field it becomes analysable, frameable, manipulable [sic], and ultimately...exploitable. (1997:207)

What clearer elucidation of the challenges of translating sounds (and images) can there be?

I want to emphasise that there is not a simplistic or ready-made formula about the value and ease of maintaining ancient cultural heritage in the modern world. I am, however, convinced that an interdisciplinary approach-or a trans-disciplinary adventure between the sciences and the creative arts - provides unique, and more exciting, strategies for teaching, learning and understanding. At the same time, developments in the new media arts enable us to visualise sensitive, friable, vulnerable, human artworks (be they skeletal remains, tapestries or, as in the present example, footprints) in a manner that enhances our understanding of human creativity. The visualisation afforded by, for example, three-dimensional animation and immersive sound can make the experience of touching history as vivid as touching the original exhibit, whether or not that is physically possible.

Similarly, the conservation needs of, say, rare tapestries imply a level of reduced light that makes viewing them nearly impossible for the sight-impaired. Happily, the digitised and dramatised version of that tapestry on the interactive computer screen brings the artefact to life as never before. Instead of simply 'being there', we become there - and this concept of formative discovery is a fascinating and liberating one for those who teach art, design, sculpture, new media arts, music, art theory and many related disciplines. Let me give a further instance of the context of the footprint site. It is that every discovery carries with it both risks and triumphs. In the case of the Willandra Lakes site, the very process of opening 
up this vast treasure chest of knowledge has made the site both more secure and more vulnerable - at exactly the same moment.

It is theoretically more secure because the Australian Museum in Sydney has organised the creation of plaster casts of some of the iconic prints and has arranged ground-penetrating radar scanning of the location, 80 per cent of which has been completed. Those very processes (and others associated with them) have, however, put the site at increased risk. The very opening up of what has been hidden for more than 20000 years has meant that the elements can now attack the site, feral animals (and humans) can potentially degrade the landscape, scientists (instead of Aboriginal people) can claim the discovery - and have done so - and, as I have observed, the control of imagery and sound (in intellectual property terms) has become very difficult to maintain.

So, while there has been an intense flurry of concentrated activity, to date, the traditional owners of the area - those who discovered the site, who have a custodial relationship with it and who, more than anyone else, feel its sacredness - have up to now had no success securing support for a research, art and education centre that could interpret and explain the footprint track-way. Nor have they garnered enough backing to create a 'keeping place' or archive of remembrance, for this, and future, discoveries and repatriations. What they do have are very clear aspirations for its future control, use and management - and to imagine a future that is radically translated in their favour.

This could come, and many wish it so, but the future prospects for the site are both liberating and limiting. The Australian Museum and the NSW Parks and Wildlife Service (NSWPWS) are engaged in establishing a so-called 'management plan' for the zone, but serious questions remain. Above all, in a World Heritage Area such as the Willandra Lakes, whose world is it, and whose heritage is being managed? Australia has a stake here, as do instrumentalities such as the NSWPWS and governments. Equally, however, the United Nations has a role to play, via UNESCO - as does the international and national archaeological community and, I would argue, those of us in academia (especially in music and the creative arts) who recognise the pivotal importance of such discoveries for our own pedagogy. The pastoralists of the region also play a central part: they are involved in the joint management of the park at all levels. Crucially, so are the Indigenous traditional owners. Their foundational roles of discovery, pride and custodianship underlie the entire future, and the future performance, of the Willandra Lakes World Heritage Area.

Meanwhile, the ultimate irony is that the site itself has essentially disappeared at present; it has been effectively reburied with sandbags for its own protection. This is because its uncovering in 2005 led to serious damage in a freak weather event in June 2006, when three consecutive days of rain filled the area with water, to be followed by several days of sub-zero temperatures and frost. Ice 
penetrated the aeons-old striations and caused many to be damaged. When temperatures rose, the ice expanded and melted. It is sobering to think that in just 20 months, human intervention occasioned more damage to the footprint site than 20000 years of weathering and erosion.

This raises some powerful practical and ethical questions: does the 'translation' of a special area such as this one into contemporary understanding inevitably imply its degradation? Who really owns the site? Should the footprint track-way therefore remain covered? In ethical terms, should it be allowed to erode, since years of natural weathering allowed it to become uncovered in the first place? Should a fully fledged replica be built, either above or near it - or would this be a travesty of any notion of authenticity? Should the site be roofed? Should we continue to visit the area for educational purposes? Should it be dug up and relocated? Should it be installed in a university, an art gallery or a museum? Should it become an open-air museum in its own right? Should it become established as a focal point for Indigenous-owned cultural tourism? Should it not be visited at all? And who will make these decisions?

The point is that these are potent issues of heritage, history and human behaviour, and each decision has an implication, a value and a narrative of - and through - the authenticity that surrounds it. Ironically, given the ambivalent relationship that some of the elders have had with the communications media, the very revelation of the footprint site in face-to-face mode has made it even more essential that the future preservation of the site is, for example, through the new media arts, via three-dimensional visualisation and animated imagery. A version of the Willandra track-way that utilises the sophisticated artistic and imaging techniques developed for such productions as Walking with Dinosaurs could just be the answer, and will liberate - rather than constrict - the storytelling potential that lies there. This is a significant area in which the academy (and within this the creative arts) can play an active and pivotal role-and it will.

There is no doubt that the Lake Mungo footprint site is an unparalleled case study, in which questions of philosophy, translation and authenticity take centre-stage - as do issues of the control of imagery, tourism, sound-scapes, the arts, archaeological discovery and the redefinition of Australian (and world) history. Finally, there is the question of governmental clarity: a World Heritage Area is the very clear responsibility of the Australian Federal Government while, in the main, the Lake Mungo area has been managed in the past 25 years at the local, conservational and developmental level by the State Government of New South Wales. The relationship between the two is one crucial index of the harmony (or lack of partnership) that characterises the management of the Willandra Lakes zone. 
One can only hope that the narrative and sound-scape so deeply imbued in Lake Mungo continue to be evoked in such a way that the Aboriginal owners, discoverers and true interpreters of the site continue to act as its creative custodians. The question of who writes that future into being - of who literally 'authors that authenticity' and, perhaps, who performs it in translation - is both searing and pressing. And that provides, in world terms, the greatest challenge of all.

\section{References}

Feld, Steven 1984, 'Sound structure as social structure', Ethnomusicology, vol. 28, no. 3 .

Laske, O. 1978, 'Review of The Tuning of the World, by R. Murray Schafer', The Musical Quarterly, vol. 64, no. 3.

Lawrence, Helen (ed.) 2006, Mungo Over Millennia: The Willandra landscape and its people, Maygog Publishing, Sorell, Tasmania.

Lysloff, René T. A. 1997, 'Mozart in mirrorshades: ethnomusicology, technology, and the politics of representation', Ethnomusicology, vol. 41, no. 2.

Muecke, Stephen 2004, Ancient and Modern: Time, culture and indigenous philosophy, UNSW Press, Sydney.

Schafer, R. Murray 1977, The Tuning of the World, McClelland and Stewart, Toronto.

Webb, Steve, Cupper, Matthew and Robins, Richard 2006, 'Pleistocene human footprints from the Willandra Lakes, southeastern Australia', Journal of Human Evolution, vol. 50, no. 4. 